\title{
HACIA UNA EPISTEMOLOGÍA RADICAL DE LA DESCOLONIZACIÓN
}

\section{TOWARDS A RADICAL EPISTEMOLOGY OF DECOLONIZATION}

\author{
Ernesto Herra Castro \\ Universidad Nacional de Costa Rica \\ ernesto.herra.castro@una.cr
}

Miguel Baraona Cockerell

Universidad Nacional de Costa Rica

baraona_miguel@hotmail.com

Recibido: 10/02/2016 - Aprobado: 16/09/2017

\section{Resumen}

Este artículo muestra cómo el tipo de pregunta que atraviesa el quehacer filosófico y científico está marcado por relaciones de dominio propias de la tradición greco-romana, la cual ha invertido el sentido mismo de la ciencia, fetichizando las posibilidades para producir y reproducir la vida. Se intenta impulsar, con este artículo, la generación de un horizonte otro de sentido donde la vida sea posible y tenga sentido vivirla.

Palabras clave: epistemología, ideología, fetichismo, filosofía, ciencias sociales, anticolonialismo

\section{Summary}

This article shows how the type of question that crosses the philosophical and scientific work is marked by relations of domain characteristic of Greco/Roman tradition, that has twisted the own sense of science fetishizing the possibilities to produce and reproduce life. It tries to promote the generation of an other horizon where life is possible and it would make sense to live it.

Keywords: Epistemology/Ideology/Fetish/Philosophy/Social Science/Anticolonialism 


\section{Surgimiento de la pregunta como impulso de las relaciones de dominio}

El tipo de pregunta con el que la Grecia clásica (siglos IV-III a.C.) establece relaciones de dominio, control e imposición sobre el otro tiene que ver con el desplazamiento que esta estaba experimentando por Macedonia en la dinámica comercial de la época, la cual giraba en torno al mar Mediterráneo.

La pregunta planteada se construyó desde el cómo controlar los embates de sus enemigos al tiempo que se imponía sobre otros pueblos.

El impulso de la pregunta planteada se basó en el cálculo aritmético de aquellos interesados en dividir y no en el horizonte geométrico, contenido en la racionalidad matemática, de la búsqueda del equilibrio. Lo peor del caso es que esta pregunta y los presupuestos sexistas/racistas/clasistas/antropocéntricos, contenidos en ella, se han impuesto hegemónicamente a escala planetaria y reta, en la actualidad, la posibilidad de producir y reproducir la vida a futuro.

Nos interesa, en este breve documento, problematizar y pensar a la "ciencia formal", aquella preocupada por el formalismo positivista que aspira al orden, a la dominación, a la estandarización de la ciencia, como uno de los mecanismos ideológicos a través del cual la aristocracia y la oligarquía han logrado reproducir los mecanismos de control institucional contenidos en el proyecto greco-romano.

La dinámica expansionista con que este proyecto civilizatorio greco-romano se ha logrado imponer hegemónicamente alrededor del planeta tiene que ver con la noción ideológica en tanto "imagen invertida” (Marx), que orienta a la "ciencia formal" y al lugar que esta ocupa en la centralidad de la actual fase hipermoderna (Baraona, 2011) del proyecto civilizatorio anteriormente señalado.

En este breve trabajo nos interesa develar los pilares sexistas/racistas/ clasistas/antropocéntricos contenidos en el proyecto de la modernidad e institucionalizados, en tanto presupuestos, en la forma de proceder de la "ciencia ideológica" (Marx) como continuidad del expansionismo greco-romano posterior a 1492. Al hacer lo anterior nos interesa asumir la responsabilidad de pensar el tipo de preguntas pertinentes para hacer la vida posible a futuro, ya que el tipo de epistemología del poder (Quijano, 2000) 
que se nos ha impuesto no solo ha borrado nuestro pasado, sino que nos ha imposibilitado plantear nuestras propias preguntas.

El presente artículo es el resultado de la reflexión crítica establecida en el marco del proyecto Epistemologías del Sur: Red de Pensamiento Anticolonial Respecto de lo Migratorio, lo Educativo y lo Rural. Al equipo académico y estudiantil que forma parte de este equipo le agradecemos la oportunidad de pensar con ustedes.

\section{Pilares de las relaciones de dominio contenidas en la expansión del proyecto greco-romano}

La dinámica expansionista con la que el proyecto greco-romano se ha impuesto sobre otros pueblos, dinámica que en la actualidad amenaza la permanencia helena en la Unión Europea, se ha desarrollado desde el despliegue de un tipo de racionalidad que justificó la superioridad ateniense sobre el resto de la especie humana y todas las otras formas de vida.

El tipo de pregunta desarrollada en la Grecia clásica (siglos IV y III a.C.) está ubicada en un contexto de intensas confrontaciones bélicas en el que Atenas, Esparta y Macedonia se disputan el control del comercio marítimo que gira en torno al mar Mediterráneo, en el cual Macedonia culminaría por imponerse y desplazar a Atenas del centro de las relaciones comerciales que alguna vez ocupara. De esta forma, el horizonte de sentido contenido en la pregunta helena aspira prevalecer a los embates de sus enemigos al tiempo que se impone sobre otros pueblos. Para lograr lo anterior se requirió un ejército entrenado y preparado para la guerra, pero para que este lograse ser desplegado en el campo de batalla con inteligencia y eficacia se requirió la justificación racional que respaldara la superioridad humana del pueblo heleno frente a la inferioridad cuasi humana o animal de los otros.

El proyecto expansionista que inició el rey Filipo de Macedonia y que continuó su hijo Alejandro, quien llegara a convertirse en Alejandro Magno, contó con el fundamento filosófico de Aristóteles, quien fuera tutor de Alejandro desde el 434 a.C. hasta el año de su muerte en el 323 a.C., el cual le permitió a aristócratas y oligarcas crear una "comunidad de guerreros" que "sólo debe pensar en obedecer y no en intentar revoluciones" (Aristóteles, 2007, p. 44). 
De esta forma los presupuestos sexistas/racistas/clasistas contenidos en la filosofía helena, que son el fundamento con que se impone en la actualidad la desigualdad moderna (Baraona, 2011), se instalan y reproducen en el derecho romano, la teología cristiana, la política, la ciencia moderna y el mercado capitalista, de forma tal que los privilegios que alguna vez fueran solo de hombres atenienses, poseedores de recursos materiales, reconocidos socialmente como mayores de edad, que supieran leer y escribir han sido complejizados y extendidos más allá de Atenas, siendo en la actualidad privilegios que giran en torno a lo ${ }^{1}$ masculino, lo occidental, lo blanco en términos de pigmentación, lo heterosexual, lo cristiano, lo adulto, lo capitalista, etc., que son los atributos del sujeto en condición de hacer la política, la filosofía y la guerra (Herra y Baraona, 2015).

El presupuesto sexista del que parte el horizonte de sentido heleno tiene sus cimientos en el mito fundador del Olimpo (Detienne, 2005), que ha institucionalizado el hecho de que las mujeres pierdan lugar en la política, institución maternal por antonomasia, sino que pierden su derecho a ser reconocidas como una "otra" humana, ser llamadas "atenienses" y, por lo tanto, ser objeto de dominio del proyecto "democrático" contenido en la "política” pensada por Aristóteles, quien señala “...la relación de los sexos es análoga; el uno es superior al otro; éste está hecho para mandar; aquel para obedecer" (Aristóteles, 2007, p. 19).

Asimismo, Pandora, primera mujer enviado por Zeus del Olimpo, es comprendida por la racionalidad helena como "desgracia hermosa". Lo anterior deja en evidencia que el orden sexista contenido en el proyecto heleno goza de la venia divina de su pensamiento mítico, así como el cristianismo lo ha acuerpado y reproducido en su noción mitológica.

Ser hombre no es suficiente para ocupar posiciones de superioridad en el orden vertical trazado por el proyecto heleno, el cual es solo posible de ejecutar en la medida en que se cuente con la fuerza de trabajo en condiciones de esclavitud, la cual transfiere a la dinámica económica helena

1 Dado que las dinámicas modeladas en torno al nuevo orden étnico colonial (Baraona, 2011), estructurado a partir de la imposición colonial de la Europa latino-germánica en el Anáhuac, el Abya-Yala y el Tawantinsuyu, hoy la "idea de América Latina" (Mignolo, 2007) desde 1492, permiten la dirección del principal Estado capitalista europeo por una mujer, o que el legado imperialista romano, asumido como "Destino manifiesto" por los Estados Unidos, sea dirigido en la actualidad por un hombre negro, quiere decir que el orden y los presupuestos sexistas/racistas/clasistas con que se reproduce el proyecto contenido en la modernidad han sido confrontados. De esta forma creemos que el artículo neutro lo nos permite hacer esto visible. 
el plustrabajo absoluto de un porcentaje cercano al 70\% de la población de Atenas. Dado que para someter a otro a trabajo forzado en condiciones de esclavitud, además de institucionalizarla debido a la trascendencia económica que esta tiene para la dotación material del proyecto heleno, es necesario contar con una justificación racional. Aristóteles tiene claro que quien “... por una ley natural no se pertenece a sí mismo sino que, no obstante de ser hombre, pertenece a otro, es naturalmente esclavo" (Aristóteles, 2007, p. 18).

La justificación "natural" de que la esclavitud en tanto institución económica y social, pensada por Aristóteles como "instrumentos de producción", permite estructurar un complejo aparataje institucional en el que "el hombre puede aumentar ilimitadamente sus riquezas" (Aristóteles, 2007, p. 26). Para lograr lo anterior es necesario justificar la superioridad helena, lo cual es evidente tras la imposición colonial que esta ejerce sobre aquellos pueblos cuyas formas de comprender el cosmos y relacionarse con él se estructuraban al margen de la ciudad-Estado, quienes podían ser considerados como seres "degradados" (Aristóteles, 2007). En este sentido, Atenas no es cualquier ciudad. "Fuera de Atenas no hay nada más que ciudades compuestas, ciudades con mezclas de todos los orígenes. Sólo los atenienses son autóctonos puros -sin mezcla-, sin aleación de no-autóctonos" (Detienne, 2005, p. 18). Los "otros"” son aquellos sobre los que se construyen relaciones de inferioridad que han permitido a la aristocracia y la oligarquía gozar de privilegios que los ubica socialmente en condiciones de superioridad. En su texto Menéxeno Platón señala:

Así es en verdad de segura y sana la generosidad y la independencia de nuestra ciudad, hostil por naturaleza al bárbaro, porque somos griegos puros y sin mezcla de bárbaros. Pues no habitan con nosotros ni Pelops ni Cadmos ni Egiptos o Dánaos, ni tantos otros que son bárbaros por naturaleza y griegos por la ley, sino que habitamos nosotros mismos, griegos y no semibárbaros,

2 En nuestro contexto actual, este grupo estaría compuesto por las representaciones diversas de lo femenino, lo negro, lo autóctono, lo joven/infantil, lo sexualmente diverso, lo no democrático, lo no cristiano, etc. Este sector del "otro", en la actualidad, no tiene un sexo, una pigmentación, una sexualidad, un credo, un oficio en específico. Sin embargo, representa todo aquello que no ha estado vinculado históricamente con el poder o que, en su defecto, ha optado por resistir en términos comunitarios, para la producción y reproducción de la vida, y no en términos de adaptarse al orden social, mediado por la formalidad de contratos administrativos formales cuyo horizonte de sentido es la producción y reproducción de la institucionalidad moderna. En esta dinámica histórica de adaptación/resistencia es que se teje nuestra historia colonial. 
de donde el odio puro a la gente extranjera de que está imbuida nuestra ciudad (245d).

Ese "odio puro" no es otra cosa que el odio a la naturaleza del otro, allotría physis, tal como lo piensa Platón.

La necesidad de expandir el Estado, a través del proyecto civilizador heleno, partía del principio de que la naturaleza había sido creada para la satisfacción de las necesidades de los hombres, a quienes los helenos no solo comprendían en términos de totalidad, por ser el mayor estadio de desarrollo evolutivo de la humanidad, sino que estos estaban en la obligación de mostrarles el camino de la "civilización" a los pueblos bárbaros e incivilizados. Lo anterior invitó a los helenos a comprenderse de manera escindida de la naturaleza, lo cual se evidenció en la posición de sujeto que jugaron en el tipo de relacionamiento analítico en el que el objeto es determinado y explicado por este, que es solo sujeto frente a un objeto. De esta forma la comprensión de la realidad en tanto physis (naturaleza) y nomos (cultura en tanto producción humana) ha acompañado los distintos proyectos imperiales gestados por la intelectualidad académica occidental u occidentalizada y han sido perpetuados por un ejército con "toda clase de placeres", ya que “... si los miembros defensores de la ciudad no son dichosos. ¿Quién aspirará a serlo?" (Aristóteles, 2007, p. 51).

Para lograr lo anterior es necesario desarrollar una "ciencia de adquirir... que tiene principalmente por objeto el dinero, y cómo su fin principal es el de descubrir los medios de multiplicar los bienes, porque ello debe crear la riqueza y la opulencia" (Aristóteles, 2007, p. 29). Es este, a nuestro criterio, el momento en el que la ciencia, como mecanismo de dominio, de control, de imposición, se piensa como un dispositivo técnico del tipo de racionalidad alrededor del que gira el aparataje institucional estructurado alrededor del proyecto heleno, de forma tal que, a partir de este momento, la ciencia se piensa como el mecanismo a través del cual la riqueza y la opulencia "ilimitadas" deben ser posibles. A esta ciencia, que es la "ciencia de adquirir", se le opone la "ciencia doméstica", la cual tiene por horizonte de sentido la vida.

Esta "ciencia doméstica" no se impone a la naturaleza, como sí lo hace la "ciencia de adquirir". La "ciencia doméstica" identifica en la naturaleza no 
solo un ser vivo igual que este, sino que la identifica como la madre que le ha dado la vida y es por ello que Aristóteles la responsabiliza de brindar los primeros alimentos. Para el filósofo heleno a esta le "corresponde asegurar el alimento al ser que ha creado, pues en efecto, todo ser recibe los primeros alimentos del que le transmite la vida" (Aristóteles, 2007, p. 30). De esta forma Aristóteles, además de fuente de vida y alimentación, identifica en la naturaleza la fuente generadora de riqueza.

Aristóteles comparte la tradición filosófica iniciada por Tales hacia el 625 a.C., la cual será retomada posteriormente por Occidente para justificar la brutalidad con que se ha impuesto el ser humano sobre toda forma de vida en la Tierra. Según esta forma de proceder "la capacidad de los seres humanos de someter la naturaleza a sus propias necesidades se debe a la superioridad 'espiritual' que los seres humanos tienen sobre la naturaleza" (Ricoeur, 2012, p. 85).

Marx señala en los Manuscritos económicos y filosóficos de 1844 que la orientación de la actividad filosófica está fundada en la actividad económica que define su horizonte de sentido, reproducido a través de la ciencia, particularmente "la ciencia de adquirir". Según Ricoeur (2012) para Marx "la religión, la familia, el Estado, la ley, la moral, la ciencia, el arte, etc., son sólo modos particulares de producción sujetos a la ley general de ésta” (p. 100). A partir de lo anterior, quisiéramos señalar que la pretensión totalizadora y universalizante contenida en la tradición greco-romana, que posteriormente es continuada por el tipo de racionalidad latino-galo-anglo-germana y que ha sido impuesta en el Anáhuac, el Abya-Yala y el Tawantinsuyu, tiene más relación con lo que Marx denomina "ideología” en tanto "imagen invertida”, que con la pretensión de alcanzar "conocimiento verdadero".

La tradición greco-romana, que es secuestrada por la Europa latino-germánica a partir de los siglos XII y XIII (Ilustración), logra expandirse debido a que el saber, como condición de los hombres libres (Aristóteles, 2007), "se convierte en una fuerza social y pasa a estar en función de las exigencias prácticas de la vida política” (Saavedra, 2013, p. 21). De esta forma el postulado socrático "conócete a ti mismo", que se inspira en el pensar conceptual para determinar lo que es "universalmente válido", culmina por convertirse en "ciencia verdadera" que es aquella "que produce resultados y promete 
dominio sobre hombres y cosas; la que garantiza inversiones, al ser promesa de ganancias" (Serrano, 1988, p. 21).

\section{Epistemología, ciencia e ideología}

Al iniciar el periodo Neolítico, hace unos 12000 años, los distintos clanes, tribus y pueblos que, por primera vez, poblaron la redondez de la Tierra hicieron posible su vida comunitaria alrededor de la acción económica. Esto le ha permitido a nuestra especie organizar la producción, la distribución y el intercambio en función de las dinámicas de consumo que hacen posible la reproducción de la vida comunitaria a futuro.

Si bien los clanes, tribus y pueblos originarios de lo que la colonización nombró como América, África o la India se organizaron alrededor de "sistemas económicos equivalenciales", en los que "quienes trabajan y gestionan el sistema son los mismos actores en comunidad de patrimonio, uso y consumo, y forman por ello una comunidad igualitaria" (Dussel, 2014, p. 45), otros pueblos no lo hicieron así. En algunos grupos de la especie humana los recursos se concentraron alrededor de

Unos pocos, los dominadores, [quienes] poseyeron de diversas maneras dicho excedente. Esto los convertía en los sujetos del ejercicio del poder monárquico (desde las más antiguas ciudades mesopotámicas), sacerdotal (como en Egipto), guerrero (como entre griegos y romanos), feudal (en la Europa germánica), letrado (como entre los mandarines en China), o propiamente económico (como los industriosos y comerciantes, siendo frecuentemente eunucos, que poseían bienes a las órdenes del emperador chino), o, por último, burgués (que también se inició en el mundo islámico, pero que floreció en Europa moderna de ciudadanos libres con propiedad privada ante la nobleza monárquica feudal, al comienzo, y ante las masas empobrecidas, después) (2014, p. 79).

Las formas de organización de la especie consigo misma y las otras formas de vida prevalecientes son claro reflejo de las disputas que han surgido entre las distintas comunidades, desde la transición del Paleolítico al Neolítico, por asegurar el control de los recursos disponibles. Lo anterior significó "un creciente dominio sobre técnicas e instrumentos de gestión 
y acumulación de los excedentes (logrados frecuentemente por un exceso de trabajo) que la comunidad toda producía gracias al crecimiento de los sistemas económicos que se fueron organizando" (Dussel, 2014, p. 45).

La organización de la humanidad en torno a sistemas comunitarios y sociales complejos tuvo a la producción y reproducción de la vida como horizonte de sentido. La posibilidad de nuestra especie de producir excedentes, es decir, más de lo necesario para hacer posible la vida, es una condición sin la cual nuestra especie no podría asegurar su futuro. De esta forma, los distintos sistemas estructurados por los grupos humanos se organizaron en torno a la producción, la gestión, la distribución y el consumo de los excedentes de la producción comunitaria (Dussel, 2014).

El deseo o necesidad que da impulso a la producción del satisfactor de ese deseo o necesidad es el fundamento de la realización del esfuerzo para modificar la naturaleza y extraerle un producto. Dado que el producto del deseo o la necesidad son el resultado de la transformación de la "mera cosa real natural" (Dussel, 2014) en su satisfactor, Marx le denomina trabajo objetivado, ya que está fuera del sujeto, pero este es producto del despliegue de su fuerza de trabajo, en tanto "trabajo vivo". Según Ricoeur (2012), "la objetivación es el proceso en virtud del cual algo interior se externaliza y de esa manera se hace actual, real...” (p. 81).

Lo anterior permite identificar que todo producto, toda mercancía, si es que ya ha sido reducido a la determinación del mercado, son productos humanos, así como lo son la religión, la tecnología o la ciencia. Estos productos son la expresión intelectual y material de que "el hombre produce al hombre" (Marx, 1968) y que esto ha sido solo posible a través del dominio técnico e instrumental para la acumulación de los excedentes del trabajo comunitario. Sin embargo, el modelo feuerbachiano, expresado en la lógica de Hegel, en la que falsamente se proyecta hacia arriba la producción humana como "lo eterno, lo lógico, lo trascendente, lo abstracto, lo divino", desplaza del lugar de creación al sujeto y lo ubica ahora en el lugar del predicado. Ricoeur (2012) señala que

Mientras que en la realidad la humanidad es el sujeto y lo divino es un predicado es decir, una proyección del pensamiento humano la religión transforma 
este predicado divino en un sujeto, en un Dios y lo humano se convierte en un predicado de este sujeto absoluto (pp. 70-71).

Los presupuestos de los que parte Aristóteles cuentan con la venia del Olimpo y le permiten, al pensador de Estagira y los suyos (oligarcas y aristócratas), hacerse del control de las dinámicas de producción, gestión, distribución y consumo de los excedentes de la producción. Lo anterior lo logra solo a través del control estructural del aparato institucional contenido en el Estado heleno, organizado sobre la base material de una población esclava que se estima cercana al 70\% de la población de Atenas, en la que el orden aristotélico es pensado. Dussel (2014) plantea que

En el esclavismo, el sujeto humano del trabajo vivo será comprado íntegra y sustancialmente como cosa, y de inmediato subsumido como determinación interna de un proceso de trabajo (...) para que la totalidad del valor creado por dicho trabajo-esclavo sea propiedad del posesor del mismo sujeto de producción (del esclavo) (p. 60).

Lo anterior permite comprender a la filosofía helénica como el despliegue racional del proyecto político de aristócratas y oligarcas, cuyo horizonte de sentido tiene que ver con garantizar la reproducción de un orden social estructurado a su alrededor. De esta forma, el conjunto de jerarquías de poder estructuradas en torno a este proyecto político ha tendido a ubicar a este reducido sector de la sociedad global por encima de la "línea divisoria de lo humano" (Grosfoguel, 2011).

Los presupuestos sexistas/racistas/clasistas contenidos en el proyecto heleno han sido trasladados al derecho romano desde el momento en que Grecia y Roma se fundan en un solo pueblo en el siglo II a.C. Estos presupuestos, pilares constitutivos del proyecto imperial cristiano, son los cimientos con los que la Iglesia cristiana se expandiera a lo largo y ancho del mundo conocido, después de que Constantino la hiciera Iglesia del Imperio en el siglo IV d.C.

Si bien los postulados epistemológicos de la ciencia moderna han variado y se distancian, algunos de ellos, de los de la ciencia antigua, es importante sacar a la luz el hecho de que el horizonte de sentido del proyecto heleno y el latino-germánico podrán distanciarse en la forma en que se presentan sus 
formalismos lógicos, mas no en su fondo. En este sentido compartimos el señalamiento crítico de Marx, en Ricoeur (2012), respecto de que "la economía funda las orientaciones de la filosofía” (p. 76) y que así como hombres/ libres/atenienses/poseedores de recursos materiales/letrados se impusieron como el sujeto en condición de hacer la política, la filosofía y la guerra en la Grecia clásica (siglos IV y III a.C.), los aristócratas, oligarcas, comerciantes, guerreros y el clero necesitaron del despliegue de una racionalidad que justificara la imposición militar, epistémica, cultural, etc., sobre un pueblo que, teniendo alma, historia y saberes sensibles para hacer la vida posible, necesitaban ser integrados y subsumidos en las dinámicas esclavistas de la tradición greco-romana. De esta forma la dinámica saber/poder instituida en la tradición greco-romana pone de cabeza su sentido impulsor, en tanto institución dotadora de vida, y lo sitúa como "una fuerza social y pasa a estar en función de las exigencias prácticas de la vida política” (Saavedra, 2013, p. 21), poniendo de cabeza el sentido mismo del saber, en tanto hecho dado para hacer la vida y reproducir la vida que es posible solo en la medida de "ser-siendo" y "estar-estando" (Zemelman, 2012), y ubicándolo ahora en el formalismo institucional que jerarquiza unos saberes sobre otros desplazando, inferiorizando, subordinando, extinguiendo, desapareciendo, olvidando las muchas historias y realidades de las que formamos parte como especie.

Los presupuestos contenidos en el proyecto de la modernidad, que son los que impulsa la metafísica aristotélica, fundan las bases de la lógica formal, orientada hacia el impulso de la "propiedad particular" en lugar de la "comunidad de bienes” (Aristóteles, 2007); están subsumidos en el pensamiento moderno y la epistemología de las ciencias que impulsan la separación "ser humano/naturaleza" del pensamiento baconiano, la idea de autonomía en Kant, el concepto de espíritu en Hegel o de ser de la especie en Feuerbach. Esto es solo reflejo de que el "creciente dominio sobre técnicas e instrumentos de gestión y acumulación de los excedentes de la comunidad" (Dussel, 2014, p. 45) le exige a la "clase gobernante" de la tradición greco-romana imponer sus intereses, sus criterios y el saber que los fundamenta como verdaderos y universales. De esta forma el clasismo, en tanto pilar constitutivo de la racionalidad helena-latina-moderno-occidental, necesita "alcanzar su fin como los intereses comunes de todos los miembros de la sociedad, es decir, expresados en una forma ideal: esa clase tiene que dar a sus ideas la 
forma de la universalidad y representarlas como las únicas ideas racionales, universalmente válidas" (Ricoeur, 2012, p. 132). Lo anterior permite comprender el sentido de totalidad que le asigna el proyecto aristócrata y oligarca a la filosofía helena; los mercaderes, comerciantes y nobles al derecho romano; la aristocracia eclesiástica de la Europa latino-germánica a la teología cristiana (en el orden latino y posterior a la Reforma Protestante); el imperialismo occidental a la política (Maquiavelo, Hobbes, Montesquieu y otros); el orden burgués naciente de las confrontaciones entre potencias coloniales que se desarrolla en Europa, denominada Revolución Francesa (1789), a la ciencia moderna (Galileo, Bacon, Descartes, Hume, Hegel, Kant o el mismo Marx); y en la actual fase de la modernidad, que pensamos como hipermodernidad (Baraona, 2011), entendemos al mercado capitalista como el proyecto dirigido por un complejo ejército de técnicos, dispuestos a nivel global cuyo objetivo es la creación de necesidades para el mercado capitalista. De esta forma, el diverso campo de especialistas en el consumo se encarga de satisfacer el apetito del nuevo sujeto hacedor de la filosofía, la política y la guerra. Este nuevo sujeto, que es una expresión recrudecida del desplazamiento del sujeto por el predicado, solo es en tanto consume. El mercado capitalista, en tanto institución que desplaza a la ciencia moderna como una de las principales instituciones garantes de la reproducción del orden eurocentrado, se piensa y ejecuta en la actualidad desde los medios de comunicación masiva. Campo en el que el Internet ejerce tensiones y resistencias reflejo de las dinámicas coloniales que nos atraviesan.

El sujeto-consumidor ya no es colectivo, sino individual. Este se encuentra en condición de "merecer(lo)" todo y para quien el mercado capitalista está en la obligación de crear los satisfactores de sus necesidades que han contribuido a acelerar la sexta extinción masiva en el planeta.

Lo anterior permite identificar el "fetichismo" o "la imagen invertida" contenida en el largo devenir del proyecto greco-romano-latino-occidental, donde el sujeto ha sido desplazado al lugar del predicado. De esta forma la filosofía helena no tuvo reparo en inferiorizar u obviar a las mujeres, los niños, los esclavos, los extranjeros y los bárbaros de las dinámicas de apropiación del excedente de la comunidad y por ello los ubicó en posiciones de subalternidad. Queda claro que la filosofía helena tuvo mayor orientación hacia la reproducción de un proyecto de dominio que hacia sus pretensiones 
iniciales de búsqueda de la "verdad" o la construcción de conocimiento con implicaciones universales con que pensar la totalidad. Este movimiento hace que la Iglesia cristiana, en tanto institución, se confronte con los principios que impulsan su origen. Según Hinkelammert (2007)

La paradoja del mensaje cristiano es, que Dios no se hizo cristiano sino hombre. Desde el comienzo el mensaje cristiano va más allá de lo cristiano. El mensaje es, humanizarse, no necesariamente cristianizarse. La secularización del cristianismo es parte del mismo cristianismo, es su interior. El mensaje de humanizarse puede rebelarse en contra del mismo cristianismo es parte del mismo cristianismo, es su interior. El mensaje de humanizarse puede volverse contra del mismo cristianismo instituido. Se le escapa al cristianismo constituido (p. 13).

Este es el mismo principio que opera en el derecho romano y que denuncia Pablo Tarso, fundador de la Iglesia cristiana, quien

Distingue entre el pecado y los pecados. Los pecados violan la ley. Sin embargo, el pecado se comete cumpliendo la ley (...) Quien considera la justicia como resultado del cumplimiento de la ley, produce la injusticia. La ley, al ser considerada su cumplimiento como instrumento de la justicia, se transforma en su contrario: según palabras de Pablo, siendo ley de Dios se transforma en ley del pecado (Hinkelammert, 2013, pp. 17-18).

La imagen invertida que se produce en la ciencia, que hace un viraje que la niega como institución humana posibilitadora de vida, "ciencia doméstica”, y la impone como el despliegue práctico del proyecto greco-romano que desarrolla y perfecciona las relaciones de dominio de nuestra especie consigo mismo y todas las otras formas de vida. Esta percepción de la ciencia, como "ciencia de adquirir", está conducida por un horizonte de sentido donde la riqueza es ilimitada y la noción misma de naturaleza ha sido necesaria de crear para contar con un lenguaje que diera claridad del objeto que debía ser dominado. Ante esto Marx señala que hasta el carácter de la misma naturaleza es un producto de la industria y del conjunto de relaciones a través de las cuales se articula la sociedad (Marx y Engels, 1970). 


\section{Balance provisional}

Al ser la ciencia una institución humana fundamental para hacer y reproducir la vida, el control sobre los linderos a los que su saber se circunscribe se tensa con las pretensiones de dominio contenidas en la expansión del proyecto civilizatorio greco-romano.

De esta forma un saber desarrollado comunitariamente, que le ha permitido a nuestra especie afrontar enfermedades, pestes y plagas a lo largo y ancho de nuestro planeta, en tiempo-espacios muy distintos y en contextos culturales muy diversos, le es arrancado de sus manos al sujeto comunitario que le ha dado vida, y ha sido entregado, por la vía de la legalidad, a los individuos singulares garantes de la reproducción de una ciencia para la acumulación, el enriquecimiento y la opulencia ilimitadas en contraposición a una ciencia para la vida. Esto deja en evidencia que la "ciencia de adquirir" y la "ciencia doméstica" no se diferencian en sus nociones metodológicas o epistemológicas, sino en su posibilidad óntica de ser y hacer la vida posible.

El proyecto expansionista greco-romano, que atraviesa la filosofía helena, el derecho romano, la teología cristiana, la política y la ciencia moderna, y hoy contenida en el mercado capitalista que ha desplazado, en tanto institución moderna, a las anteriores, urgió de la inferiorización del otro para garantizar un orden de guerreros identificados con el proyecto de centralidad aristócrata y oligarca heleno. De esta forma mujeres, niños, extranjeros y esclavos fueron desposeídos de su humanidad, para lo cual se contó con la venia de los dioses del Olimpo. Sin embargo, ello solo fue posible una vez la naturaleza, en tanto comprensión de las otras formas de vida que no siendo humanas hacen la vida humana posible, fue concebida de manera escindida de nuestra mismidad. Esto naturalizó las relaciones de dominio de hombres, libres, citadinos, con posesiones materiales y conocimientos de escritura y lectura, sobre todas las formas posibles de vida.

Lo anterior nos permite pensar que el orden étnico/colonial contenido en la ciencia formal, que no es otra que la "ciencia de adquirir" de Aristóteles, cuyos pilares sexistas/racistas/clasistas garantizan la reproducción y expansión del proyecto civilizatorio greco-romano-latino-occidental, es producto de un giro invertido en la ciencia misma, que le inhibe de su objetivo central de hacer la vida posible, al tiempo que desplaza al sujeto que orientó su 
propósito de su lugar y lo ubica ahora en el lugar del predicado. De esta forma el desarrollo de la ciencia y su perfeccionamiento cumplen, en la actualidad, la función de la no vida, no solo por negarse a quien le dio origen, sino porque la expansión del proyecto civilizatorio greco-romano-latino-occidental hoy cuenta con la mayor capacidad de destrucción, en comparación con los imperios anteriores a la expansión colonial que la Europa latino-germánica realiza desde 1492 en el Anáhuac, el Abya-Yala y el Tawantinsuyu. Esto le ha permitido a la Europa latino-germánica contar con las bases materiales a través de las que impone su proyecto de centralidad planetaria, para lo cual ha sido necesaria la transformación estética de la esclavitud, al tiempo que desarrolla armamentos cada vez más sofisticados dirigidos hacia el aniquilamiento de todas las formas de vida posibles en el planeta.

Para contar con la posibilidad de discutir sobre una ontología otra que nos permita pensar, desde la academia, en métodos, metodologías, técnicas, teorías, tesis o hipótesis, lo primero que debemos lograr mantener es la vida y lo anterior lo afirmamos sin ánimos de caer en esencialismos. Sin embargo, dado que la expansión del proyecto civilizatorio greco-romano-latino-occidental no se ha hecho responsable por el hambre, la pobreza, la miseria, la contaminación, la destrucción y la muerte que genera a través del despliegue de su filosofía y su ciencia, nos parece oportuno pensar las preguntas pertinentes para hacer la vida posible, pero, y como una exigencia humanista, que esta tenga sentido de ser vivida.

Para hacer lo anterior debemos dirigir nuestros esfuerzos a identificar la reproducción fetichizada, o la reproducción de imágenes invertidas en nuestros campos disciplinarios que nos permita identificar el racismo contenido en el proyecto greco-romano-latino-occidental más allá de la pigmentación; el sexismo más allá del sexo con que se nace; o el clasismo más allá de las relaciones de los sujetos con los medios de producción. Se trata de impulsar horizontes de sentido articulados a otras formas de apropiación de los excedentes de la producción comunitaria, lo que sugiere partir de otros presupuestos y del desarrollo de un lenguaje que nos permita pensarnos como parte del problema colonial que señalamos.

Creemos estar en condiciones de pensar nuestra realidad de forma crítica y problemática, pero no basta con ello. Tenemos claridad en que las preguntas pertinentes para la vida exigirán una praxis coherente, colectiva, 
sensible y solidaria. En este sentido, y teniendo claridad de nuestra condición de no "ser" por no "ser" griegos, romanos u occidentales, la única posibilidad que pensamos para hacer la vida posible está en la formulación de las preguntas pertinentes que orienten este propósito. Para poder pensar en ello deberemos primero estar vivos.

\section{Referencias}

Aristóteles. (2007). La política. México: Editorial Época.

Baraona, M. (2011). Diez ensayos críticos. Costa Rica: Editorial Germinal.

Detienne, M. (2005). Cómo ser autóctono. Del puro ateniense al francés de raigambre. Argentina: Fondo de Cultura Económica.

Dussel, E. (2014). 16 tesis de economía política. México: Editorial Siglo XXI.

Grosfoguel, R. (2011). La descolonización del conocimiento: diálogo crítico entre la visión descolonial de Franntz Fanon y la sociología descolonial de Boaventura de Sousa Santos. Recuperado de http://www.cidob.org/en/publications/monographs/monogra phs/ formas_otras_saber_nombrar_narrar_hacer

Herra, E. y Baraona, M. (abril, 2015). El Estado como fundamento del proyecto imperialista. Coloquio Internacional Antiimperialismo Latinoamericano: Historia, Memoria, Tradiciones, Legados y Prácticas Contemporáneas. Centro de Investigaciones sobre América Latina y el Caribe y Vicerrectoría de Extensión, Universidad Nacional.

Hinkelammert, F. (2007). Hacia una crítica de la razón mítica. El laberinto de la modernidad. Materiales para la discusión. Costa Rica: Editorial Arlequín.

Hinkelammert, F. (2013). La maldición que pesa sobre la ley. Las raíces del pensamiento crítico en Pablo de Tarso (2a ed.). Costa Rica: Editorial Arlequín.

Marx, C. (1968). Manuscritos económico-filosóficos de 1844. México: Editorial Grijalbo.

Marx, C. y Engels, F. (1970). Manifiesto del partido comunista y otros escritos políticos. México: Editorial Grijalbo.

Mignolo, W. (2007). La idea de América Latina. La herida colonial y la opción de colonial. España: Editorial Gedisa.

Quijano, A. (2000). Colonialidad del poder, eurocentrismo y América Latina. Recuperado de: http://bibliotecavirtual.clacso.org.ar/ar/libros/lander/quijano.rtf.

Platón. (s.f.). Menéxeno. Recuperado de http://www.edu.mec.gub.uy/biblioteca_digital/libr os/P/Platon\%20-\%20Menexeno.pdf

Ricoeur, P. (2012). Ideología y utopía. Argentina: Editorial Gedisa.

Saavedra, M. (2013). Gnoseología y paradigmas epistemológicos. México: Ediciones Crisol.

Serrano, A. (1988). Los caminos de la ciencia. Una introducción a la epistemología. Costa Rica: Departamento Ecuménico de Investigación.

Zemelman, H. (2012). Pensar y poder. Razonar y gramática del pensar histórico. México: Editorial Siglo XXI. 